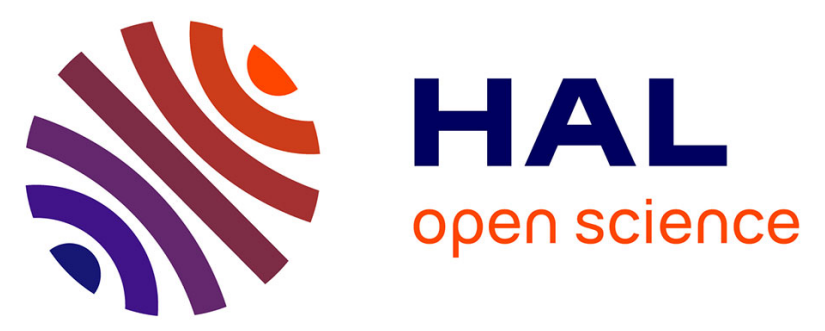

\title{
Preliminary studies for use of dynamic mechanical analysis (DMA) to verify intensity of thermal wood modifications
}

Andreja Kutnar, Robert Widmann, Iris Brémaud

\section{To cite this version:}

Andreja Kutnar, Robert Widmann, Iris Brémaud. Preliminary studies for use of dynamic mechanical analysis (DMA) to verify intensity of thermal wood modifications. International wood products journal, 2013, 4 (3), pp.158-165. 10.1179/2042645313Y.0000000044 . hal-00856618

\section{HAL Id: hal-00856618 \\ https://hal.science/hal-00856618}

Submitted on 1 Dec 2021

HAL is a multi-disciplinary open access archive for the deposit and dissemination of scientific research documents, whether they are published or not. The documents may come from teaching and research institutions in France or abroad, or from public or private research centers.
L'archive ouverte pluridisciplinaire HAL, est destinée au dépôt et à la diffusion de documents scientifiques de niveau recherche, publiés ou non, émanant des établissements d'enseignement et de recherche français ou étrangers, des laboratoires publics ou privés.

\section{(ㄷ)(1) $\$$}

Distributed under a Creative Commons Attribution - NonCommerciall 4.0 International 


\title{
Preliminary studies for use of dynamic mechanical analysis (DMA) to verify intensity of thermal wood modifications
}

\author{
A. Kutnar*, R. Widmann and I. Brémaud
}

Colour change and/or mass loss due to thermal treatment are in direct relation to the performance of thermally modified wood. The application of techniques commonly used to characterise polymers may be used to study this relationship. A standard testing procedure in the field of plastics for the characterisation of bulk properties that directly affect material performance, is dynamic mechanical analysis (DMA). DMA indicates how a material will perform in a specific application. It can be used to identify the intensity of a thermal modification by evaluation of the viscoelastic response of wood. The paper presents the method together with results of preliminary tests with Norway spruce [Picea abies (L.) Karst.] and beech (Fagus sylvatica L.). The tests showed that it is possible to thermally modify small wood specimens directly inside the DMA equipment while, at the same time, getting real time mechanical and physicochemical information about the progress of the process.

Keywords: Thermal modification, Dynamic mechanical analysis, Production process thermal degradation

\section{Introduction}

As a biological material, wood can suffer from chemical and biological degradation. At the same time, wood is one of the most important renewable materials and exhibits superior properties in many cases. Therefore, various and especially also ecofriendly methods have been developed to increase its durability, like thermal modification of wood. Industrialisation of thermal modification of wood started in the late 1980s; however, this procedure for the alteration of wood properties has been known from the beginning of the twentieth century. The exposure of wood to elevated temperatures between 150 and $250^{\circ} \mathrm{C}$ leads to a permanent alteration of the cell wall material and its physical properties. The resultant product has improved dimensional stability, a higher durability, and a darker colour. However, one downside of the thermal modification is a significant reduction of several mechanical properties, in particular strength (Widmann, 2012).

Industrial heat treatment processes are performed under a low oxygen atmosphere (Militz, 2002). Techniques commonly used are water vapour process, e.g. Thermowood, hydrothermolysis under increased pressure process, e.g. Plato, oil heat process and inert gas process, e.g. 'Bois retifié'. All of these techniques are multi-step processes where all steps have an influence on the quality of the final product. The common step in

University of Primorska, Koper. Slovenia

*Corresponding author, email andreja.kutnar@upr.si every process is the exposure to a certain treatment temperature for a defined time. These two factors are mainly controlling the intensity of the modification and thus have strong effect on the final properties of the treated wood.

The heat treatment of wood modifies the cell wall components. A number of chemical changes to heat treated wood have been reported. Sundqvist (2004) reviewed the studies of chemical changes caused by heat and hydrothermal treatment. The relevant temperatures are listed. The first chemical changes start at temperatures within the range $40-90^{\circ} \mathrm{C}$; these are predominately caused by certain extractives. The changes are seen as colour change, which are due to compounds emanating from hydrolysis of carbohydrates and extractives, and their subsequent reactions with other wood components. At temperatures within the range $90-150^{\circ} \mathrm{C}$, changes occur in all the wood components. In the case of wet conditions, approximately $100^{\circ} \mathrm{C}$ is considered to be the plasticisation temperature of wood, which is related to changes in the lignin structure. Splitting of $\beta$-aryl ethers and the formation of lignin condensation products at $100-120^{\circ} \mathrm{C}$ was found for maple, and haemolytic cleavage of phenolic $\beta$-aryl ether in wood lignin was found at around $130^{\circ} \mathrm{C}$. At temperatures of $150-250^{\circ} \mathrm{C}$, major changes occur in the wood components, both degradations and modifications. The degradation rate of wood is reported to be higher for steaming and in the presence of air during heating than for dry and air free conditions (Salmen, 1984; Olsson and Salmen 1992). In general, the influence of temperature and time is known. However, despite this a more precise analysis of the 
effects of treatment temperature and the time of the thermal treatment process might be helpful to further optimise the processes.

Various transitions in a polymer are commonly studied by dynamic mechanical analysis (DMA) (Menard 2007). DMA is a method based on harmonic tests that enables characterisation of bulk properties directly affecting material performance. DMA is a quite common method to decouple thermal activation from the time effect. DMA is a standard method for the characterisation of materials that exhibit a significant change of their viscoelastic behaviour under varying conditions. These influencing parameters can be temperature, as well as type, level and frequency of a dynamic force applied to a relevant specimen. Most often it is used for studying the behaviour of polymers, e.g. for the determination of their glass transition temperature.

DMA can be simply described as applying an oscillating force to a sample and analysing the material's response to that force. DMA enables determination of various properties of the material like the tendency to flow (viscosity) from the phase lag and the stiffness (modulus) from the sample recovery. These properties are often described as the ability to lose energy as heat (damping) and the ability to recover from deformation (elasticity). Additionally, DMA provides data on relaxation of the polymer chains and the changes in the free volume of the polymer that occur. In DMA, storage modulus $E^{\prime}$, which is a measure of the material stiffness, loss modulus $E^{\prime \prime}$, which reflects the amount of energy that has been dissipated by the sample, and the ratio $E^{\prime \prime} / E^{\prime}=\tan \delta$, index of material viscoelasticity, are calculated from the material response to the sine wave. These different moduli allow better characterisation of the material, since they enable examination of the material to return or store energy, its ability to lose energy, and the ratio of these effects, which is called damping. In a DMA test, where a specimen is heated in steps and the three parameters are plotted over temperature, a strong change of $\tan \delta$ indicates a change of the materials viscoelastic properties, e.g. the transition from a glassy to a rubbery state. As the wood components cellulose, hemicellulose, and lignin are polymeric too, it is obvious that DMA can also be used for the characterisation of wood. Depending on the environment (humidity, air, inert gas), thermal degradation and/ or reconfiguration of wood constitutive polymers can occur during the DMA tests, resulting in an evolution of measured viscoelastic properties (Assor et al. 2009). Internal friction $(\tan \delta)$ is particularly sensitive to modifications in the wood cell wall 'matrix' (lignin and hemicelluloses). Therefore, DMA as a function of temperature is a very useful tool as it provides, simultaneously, mechanical data and indications of potentially occurring chemical modifications (Laborie 2006). Owing to the high hygroscopicity of wood, DMA tests on wood as a function of temperature are usually conducted either in completely dry, or in the saturated state. However, the versatility of DMA has seldom been applied to monitor in situ the changes happening during thermal treatment processes, including several steps with different conditions.

In the present study, the DMA technique is being used for the documentation of the changes induced by thermal modification that result in viscoelastic response of the wood during heat treatment. The aim is to complement standard parameters used for the identification of the
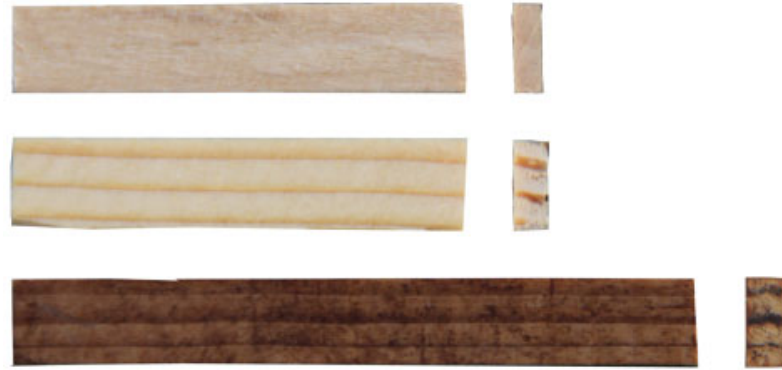

1 Top view and cross-section of specimens for threepoint bending tests in DMA equipment: from top to bottom, beech and spruce before thermal modification/ DMA with length of $30 \mathrm{~mm}$ and spruce after thermal modification/DMA with length of $45 \mathrm{~mm}$; nominal crosssection of all specimens was width $w \times$ thickness $t=6 \times 2 \mathrm{~mm}$

intensity of a thermal modification like mass loss and colour change by evaluation of viscoelastic response at elevated temperatures. Changes in viscoelastic response with increasing temperature were recorded, as well as at prolonged time at constant high temperature. The study is still in a preliminary stage and the most important first task is to determine the suitable DMA test set-ups and testing parameters that enable the comparison of the wood behaviour recorded with the DMA technique with the 'real life' changes of wood caused during the industrial thermal modification processes.

\section{Material and methods}

\section{Material}

The tests were executed with Slovenian and Swiss grown Norway Spruce (Picea abies) and beech (Fagus sylvatica). The specimens were cut from three different boards per species that were air dried. For these preliminary tests, no special sampling was conducted as for the tests it was more important to have more uniform specimens than a big variance for the representation of a whole sample. After being cut, the specimens were stored under environmental conditions of $20^{\circ} \mathrm{C}$ and $35 \%$ relative humidity until the tests started.

For the determination of the net mass loss, the oven dry mass of the specimens before the test was assessed on the assumption, that the equilibrated specimens had a moisture content of $7 \cdot 5 \%$. This moisture content could be verified on several reference specimens that were oven dried and moisture contents of $7 \cdot 3-7 \cdot 9 \%$ were determined. On this basis, the oven dry density $\rho_{0}$ of the samples was calculated (Table 1).

The nominal specimen dimensions were width of $6 \mathrm{~mm}$ (radial), length of $45 \mathrm{~mm}$ (longitudinal), and a thickness of $2 \mathrm{~mm}$ (tangential) and width of $6 \mathrm{~mm}$ (radial), length of $30 \mathrm{~mm}$ (longitudinal) and a thickness of $2 \mathrm{~mm}$ (tangential) (Fig. 1). With respect to the

Table 1 Density (mean and standard deviation) of specimens

\begin{tabular}{lllll}
\hline & Count & & Density/kg m \\
Species & $n$ & & $\rho_{0, \text { mean }}$ & $\rho_{0, \text { SD }}$ \\
\hline Beech & 22 & 600 & 32 \\
Spruce & 21 & 491 & 24 \\
\hline
\end{tabular}




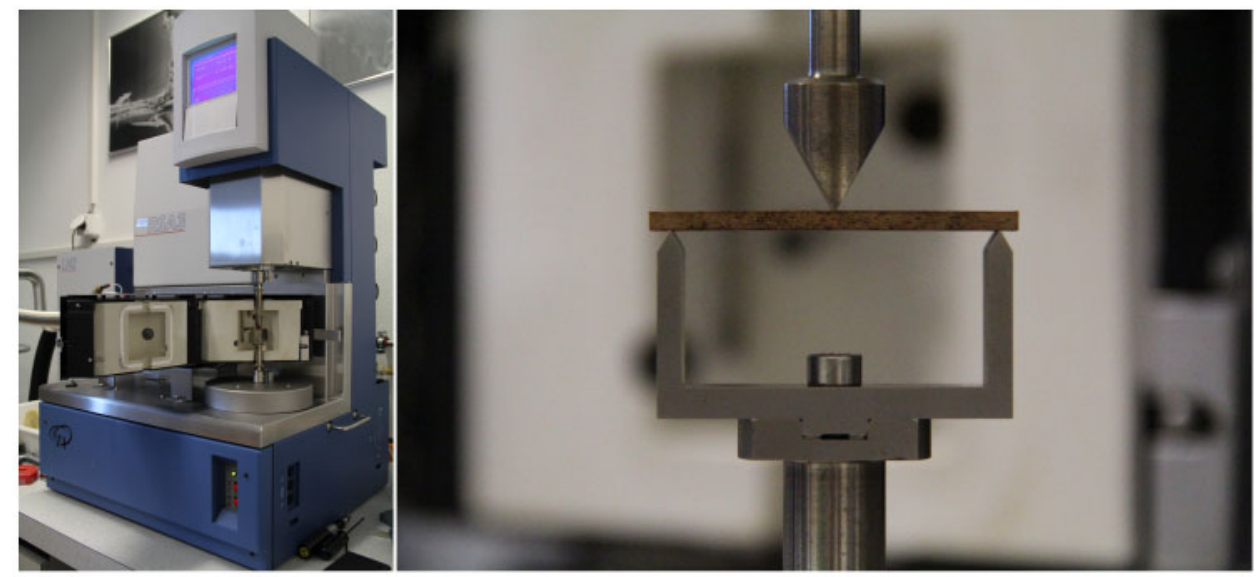

2 TA Instruments RSA III Rheometrics System Analyzer with open convection oven (left), spruce specimen after thermal treatment/DMA in three-point bending set-up with $40 \mathrm{~mm}$ span (top right)

envisaged flat bending set-up, the cutting of the specimens was aligned in such a way, that the applied loading acted in the radial direction and bending stresses resulted in the longitudinal direction.

Immediately before and after the test, the effective mass and the effective dimensions of the specimens were measured.

\section{Methods}

The used DMA was a TA Instruments RSA III Rheometrics System Analyser (Fig. 2). This DMA is equipped with a gas convection oven. The oven can be operated with ambient air or with an inert gas (nitrogen). If nitrogen is used the environmental controller enables a temperature range from -150 to $600^{\circ} \mathrm{C}$ (air: ambient to $500^{\circ} \mathrm{C}$ ). The RSA III enables the following dynamic loadings on a specimen: tension, compression, three-point bending, clamped three-point bending and shear. For the present study a three-point bending set up was chosen, with effective spans of 25 and $40 \mathrm{~mm}$ (Fig. 2).

Dynamic loading can be performed with loads up to $3500 \mathrm{~g}(34.3 \mathrm{~N})$ and amplitudes of up to $\pm 1.5 \mathrm{~mm}$ in a frequency range of $1 \times 10^{-6}-80 \mathrm{~Hz}$. For the characterisation of a material, several test modes are available. Within sweep test modes, one single parameter (e.g. frequency, temperature, strain) is varied over a defined range, while all other parameters are kept constant. For the purpose of studying the thermal degradation over time, a time sweep test would have been appropriate. However, in order to enable also the monitoring of the heating phase, a temperature ramp test mode with a successive holding ('soak') time was chosen. For temperature ramp tests, heating rates of $1^{\circ} \mathrm{C} \mathrm{min}{ }^{-1}$ are often suggested. However, for elevated temperatures, this means that some thermal modification/degradation would already happen during the heating ramp. In order to minimise this effect, a heating rate of $10^{\circ} \mathrm{C} \min ^{-1}$ was chosen, although a relatively fast heating rate could result in a temperature and moisture gradient in the test specimen and affect the measurements until equilibrium in the test specimen was achieved.

The leading parameter for the loading was the controlled dynamic strain. In a first phase, the loading was set to reach a strain of $0.02 \%$, which was later, in a second phase increased to $0.05 \%$. The main reason for this was to reduce signal noise that occurred due to the relatively low loading was linked to the $0.02 \%$ strain. For all tests, the sampling rate was set to one measurement per $30 \mathrm{~s}$ and the loading frequency was set to $1 \mathrm{~Hz}$. The different test parameters used are summarised in Table 2 . DMA temperature scans were performed in a temperature range of $50-250^{\circ} \mathrm{C}$ with the aim of obtaining the

Table 2 DMA and test parameters

\begin{tabular}{|c|c|c|}
\hline Parameter & Unit & Details \\
\hline Wood species & & Spruce, beech \\
\hline Test set-up & & Three-point bending \\
\hline Span & $\mathrm{mm}$ & 25,40 \\
\hline Oven gas & & Air \\
\hline Temperature & ${ }^{\circ} \mathrm{C}$ & $103,180-250$ in $10^{\circ} \mathrm{C}$ steps \\
\hline Temperature ramp rate & ${ }^{\circ} \mathrm{C} \min ^{-1}$ & 10 \\
\hline Soak time & Min & $150,300,450,1080,2160$ \\
\hline Relative humidity at temp. & $\%$ & $\sim 0$ \\
\hline Target strain & $\%$ & $0.02,0.05$ \\
\hline Auto tension & & Activated (compression) \\
\hline Force control & & Static force tracking dynamic force \\
\hline Static force/dynamic force & & $1 \cdot 15$ \\
\hline Initial static force & g & 100 \\
\hline Dynamic bending stress & $\mathrm{N} \mathrm{mm} m^{-2}$ & About $0.5-3 \cdot 0$ \\
\hline Dynamic load frequency & $\mathrm{Hz}$ & $1 \cdot 0$ \\
\hline Time per measure & s & 30 \\
\hline DMA data & Storage modulus, loss modulus, tan & $\delta$, temperature, force, displacement, strain, creep \\
\hline Wood data & Mass, dimensions, density, colour & \\
\hline
\end{tabular}



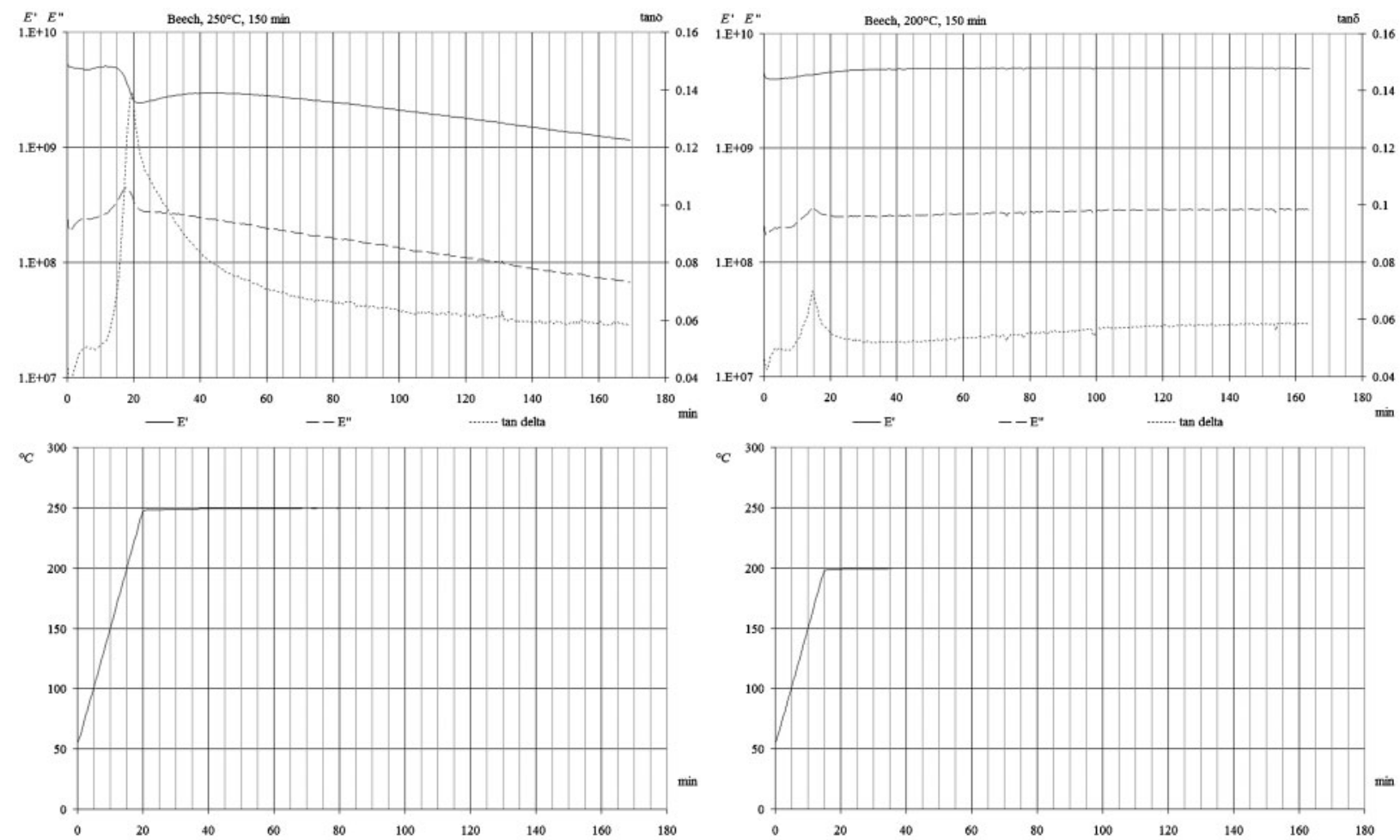

3 Viscoelastic behaviour of beech specimens at 200 and $250^{\circ} \mathrm{C}$

storage modulus $E^{\prime}$, loss modulus $E^{\prime \prime}$ and damping $\tan \delta$ of the specimens. Furthermore, DMA isothermal tests were performed at five temperature levels $(200,210,220$, 230,240 and $250^{\circ} \mathrm{C}$ ) for $2 \cdot 5 \mathrm{~h}$, with the aim of thermally modifying the specimens inside the DMA equipment. At each temperature, one beech and one spruce specimen were tested.

\section{Results}

All tests have to be regarded as being preliminary and due to the small number of specimens, as being not statistically significant. The results should be a help to set up a comprehensive test plan for the acquisition of the relevant treatment data. So far, the thermal modification was only executed under air, which enables oxidation processes within the wood that are favourable for a strong thermal degradation. In addition, humidity cannot be controlled in the DMA equipment used, and the moisture content at the treatment temperatures has to be considered as being $0 \%$ during the process. Both, oxidation and completely dry conditions are not wanted in most existing industrial heat treatment processes. However, as these conditions increase thermal degradation, it helps in this phase of the project to set up suitable DMA test procedures.

In the following, some preliminary results are presented and the importance of selected single parameters on the thermal degradation of the wood are discussed based on tests with small samples.

\section{Influence of temperature}

Figure 3 shows the progression of the three parameters, storage modulus $E^{\prime}$, loss modulus $E^{\prime \prime}$ and the damping $\tan \delta$ versus time for beech specimens that were modified under 200 and $250^{\circ} \mathrm{C}$ and a soak time of $150 \mathrm{~min}$. The modification temperature was reached after $15 \mathrm{~min}$ $\left(200^{\circ} \mathrm{C}\right)$ and $21 \mathrm{~min}\left(250^{\circ} \mathrm{C}\right)$ respectively, which is best indicated by a peak value of $\tan \delta$. At the lower temperature, both storage modulus and loss modulus slightly increase until the end of the treatment, while at the higher temperature both values decrease strongly. It can also be observed, that the storage modulus which is practically the Young's modulus appears to be relatively low.

It has to be mentioned, that the absolute values of the moduli have to be converted. The software of the DMA equipment calculates the moduli on basis of the compliance of the measured sample $\mathrm{C}$ (equation (1)) with an assumed constant cross-section as entered into the test set-up. Owing to shrinkage, the cross-section $A=w t$ and the moment of inertia $I=w t^{3} / 12$ decrease significantly and with this, the compliance $C$ increases during the modification. This results in overestimated absolute values of the moduli $E^{\prime}$ and $E^{\prime \prime}$. Table 3 shows the values for one series with beech and one series with spruce specimens. In columns $\mathrm{c}$ and $\mathrm{d}$, the loss of mass and density which is more pronounced at elevated temperature can be seen. Beech is more affected by the thermal treatment than spruce. However, the main focus of the study is on the rheometric data that are shown in columns e-k of Table 3. The measured storage moduli (also shown in Fig. 3) increase for lower temperatures and decrease with higher temperatures over time which can be seen in column $g$ of Table 3. Again, the effect is stronger for the beech specimens than for the spruce specimens. If the storage modulus is corrected according to the reduced cross-section, the temperature influence is still visible for beech, but not for spruce (Table 3, column h). One reason for this could be that the spruce specimens were about $15 \%$ thicker than the beech specimens. This results in a pronounced increase of the moment of inertia and a higher influence of shear deformations as the specimen slenderness is also lower. Therefore, it is proposed to reduce the cross-section (in particular thickness $t$ ) and/or to increase the span $l$ in 


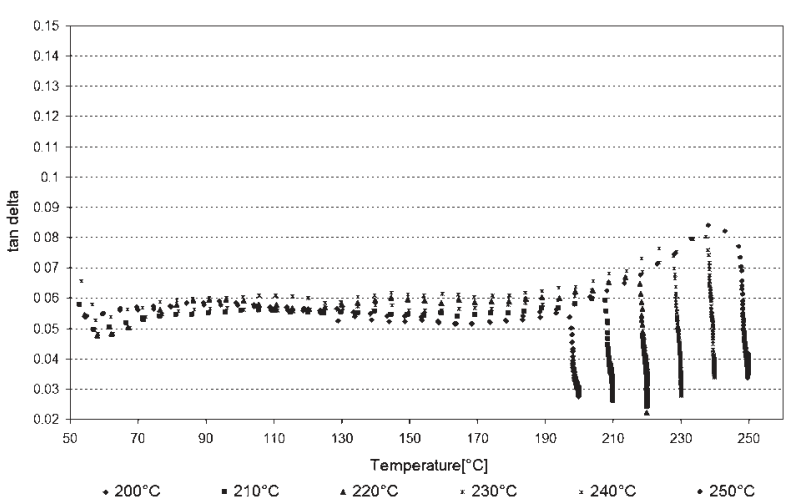

$4 \tan \delta$ of spruce wood as function of temperature for specimens tested with isothermal test in DMA equipment: treatment time at target temperature $=\mathbf{1 5 0} \mathbf{~} \mathrm{min}$

order that the specifications given in ISO 6721-5 (1996) are met. This has not been the case for most of our experiments that are presented here.

$$
C=g_{\mathrm{c}} l^{3} /\left(400 E^{*} t^{3} w\right)
$$

where $C$ is the compliance $\left(\mathrm{mm} \mathrm{kg}^{-1}\right), g_{\mathrm{c}}$ is the gravitational constant $\left(98 \cdot 1 \mathrm{~Pa} \mathrm{gm}^{-1}\right), l$ is the length $(\mathrm{mm}), t$ is the thickness $(\mathrm{mm}), w$ is the width (mm) and $E^{*}$ is the complex tensile modulus $(\mathrm{GPa})$.

The pronounced peak of $\tan \delta$ (Fig. 3) can be attributed to the heating phase where the specimens are subjected to a thermal gradient which affects their bending stiffness. It has also to be considered that the damping is low and a $\tan \delta$ in a range of $0 \cdot 04-0 \cdot 14$ equals a phase shift of $2-8^{\circ}$.

The results of DMA temperature ramp tests with soak times of $150 \mathrm{~min}$ in terms of $\tan \delta$ as a function of temperature for spruce and beech specimens are shown in Figs. 4 and 5. Tan $\delta$ is a measure of the damping property and is expressed as the ratio of the loss modulus to the storage modulus. With increasing temperature, $\tan \delta$ was increasing to approximately $90^{\circ} \mathrm{C}$, which was followed with a steady state value (most likely due to the removal of water) and after that,

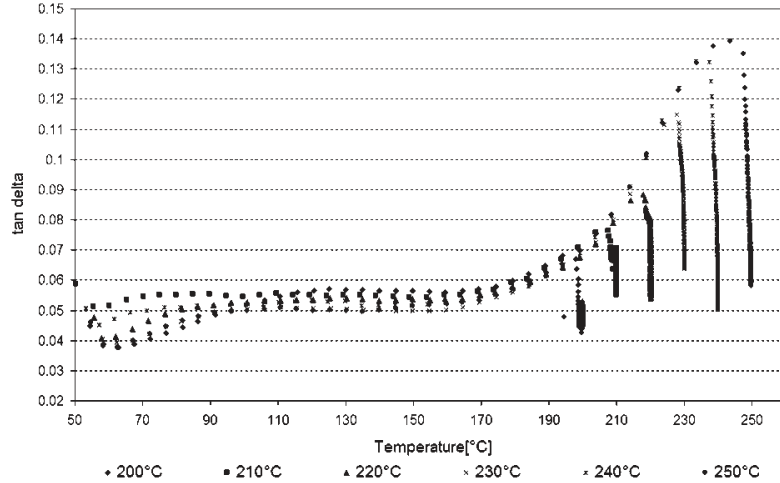

$5 \tan \delta$ of beech wood as function of temperature for specimens tested with isothermal test in DMA equipment: treatment time at target temperature $=\mathbf{1 5 0} \mathbf{~ m i n}$

starting at about $170^{\circ} \mathrm{C}$ with an increase for all examined specimens. In specimens that were heated to a higher target temperature, $\tan \delta$ was higher. The influence of temperature and time on the mechanical behaviour of beech specimens (Fig. 5) shows similar relations as for spruce specimens (Fig. 4). However, the storage modulus $E^{\prime}$ and loss modulus $E^{\prime \prime}$ of beech specimens were lower than for spruce specimens, while $\tan \delta$ was higher for beech specimens. These changes can be also described in terms of free volume changes (Menard 2007). A simple approach to looking at free volume, which is popular in explaining DMA responses, is the crankshaft mechanism, where the molecule is imagined as a series of jointed segments. The Crankshaft Model treats the molecule as a collection of mobile segments that have some degree of free movement (McCrum et al. 1991). This is a very simplistic approach, yet very useful for explaining behaviour. As the free volume of the chain segment increases, its ability to move in various directions also increases. With increasing temperature, the free volume of the chain segment of the polymers increases and consequently, its ability to move in various directions. As the temperature continues to increase, the localised bond and side chain movements and further whole main chains can occur, resulting in a decrease in

Table 3 Results of tests, influence of temperature at soak time of $150 \mathrm{~min}, 0.02 \%$ dynamic strain for beech (B) and spruce (S) specimens*

\begin{tabular}{|c|c|c|c|c|c|c|c|c|}
\hline a & b & c & d & $\mathrm{e}$ & f & g & $\mathrm{h}$ & $k$ \\
\hline & $T$ & $\delta_{\mathrm{mo}}$ & $\delta \rho_{0}$ & $E_{\text {init }}^{\prime}$ & $E_{\text {fin }}^{\prime}$ & $\delta E_{\text {app }}^{\prime}$ & $\delta E_{\text {eff }}^{\prime}$ & $\delta E^{\prime \prime}{ }_{\text {eff }}$ \\
\hline No. & ${ }^{\circ} \mathrm{C}$ & $\%$ & $\%$ & $\mathrm{GPa}$ & $\mathrm{GPa}$ & $\%$ & $\%$ & $\%$ \\
\hline B01 & 200 & $-5 \cdot 4$ & -2.5 & $5 \cdot 08$ & $6 \cdot 23$ & $22 \cdot 6$ & $44 \cdot 7$ & $69 \cdot 1$ \\
\hline B06 & 210 & -8.5 & $-4 \cdot 7$ & $7 \cdot 82$ & 6.53 & $-16 \cdot 6$ & $3 \cdot 1$ & $4 \cdot 2$ \\
\hline B03 & 220 & $-13 \cdot 7$ & $-4 \cdot 2$ & $8 \cdot 27$ & $5 \cdot 40$ & $-34 \cdot 7$ & $-10 \cdot 5$ & $-7 \cdot 6$ \\
\hline B04 & 230 & $-21 \cdot 5$ & $-10 \cdot 8$ & $5 \cdot 90$ & 3.59 & $-39 \cdot 2$ & $-10 \cdot 3$ & 14.9 \\
\hline B07 & 240 & -25.5 & $-10 \cdot 9$ & $8 \cdot 16$ & $2 \cdot 83$ & $-65 \cdot 3$ & $-43 \cdot 1$ & $-44 \cdot 8$ \\
\hline B08 & 250 & $-33 \cdot 1$ & $-12 \cdot 2$ & 5.96 & $1 \cdot 46$ & -75.5 & $-50 \cdot 7$ & $-42 \cdot 2$ \\
\hline S01 & 200 & $-4 \cdot 6$ & $-1 \cdot 3$ & 6.90 & $8 \cdot 11$ & $17 \cdot 5$ & $38 \cdot 8$ & $-8 \cdot 4$ \\
\hline S02 & 210 & -5.9 & -3.9 & $7 \cdot 31$ & $7 \cdot 34$ & 0.5 & $16 \cdot 1$ & $-41 \cdot 7$ \\
\hline S03 & 220 & -8.0 & -3.5 & $6 \cdot 02$ & $6 \cdot 78$ & $12 \cdot 5$ & $38 \cdot 4$ & $-41 \cdot 5$ \\
\hline SO4 & 230 & $-10 \cdot 5$ & -1.9 & $6 \cdot 60$ & $5 \cdot 75$ & $-12 \cdot 9$ & $19 \cdot 2$ & $-44 \cdot 8$ \\
\hline S06 & 240 & -15.9 & $-5 \cdot 2$ & $6 \cdot 85$ & $5 \cdot 39$ & $-21 \cdot 3$ & $14 \cdot 8$ & $-64 \cdot 2$ \\
\hline S08 & 250 & $-23 \cdot 2$ & $-10 \cdot 1$ & $7 \cdot 53$ & $3 \cdot 30$ & $-56 \cdot 2$ & $-31 \cdot 5$ & $-51 \cdot 3$ \\
\hline
\end{tabular}

${ }^{*} \delta_{\mathrm{mo}}$ : change of dry mass; $\delta \rho_{0}$ : change of dry density; $E_{\text {init }}^{\prime}$ : initial storage modulus; measured at $100^{\circ} \mathrm{C}$; $E_{\text {fin }}^{\prime}$ : final storage modulus; $\delta E_{\text {app }}^{\prime}$ : apparent change of storage modulus; $\delta E_{\text {eff }}^{\prime}$ : effective change of storage modulus; $\delta E^{\prime \prime}$ eff : effective change of loss modulus. 

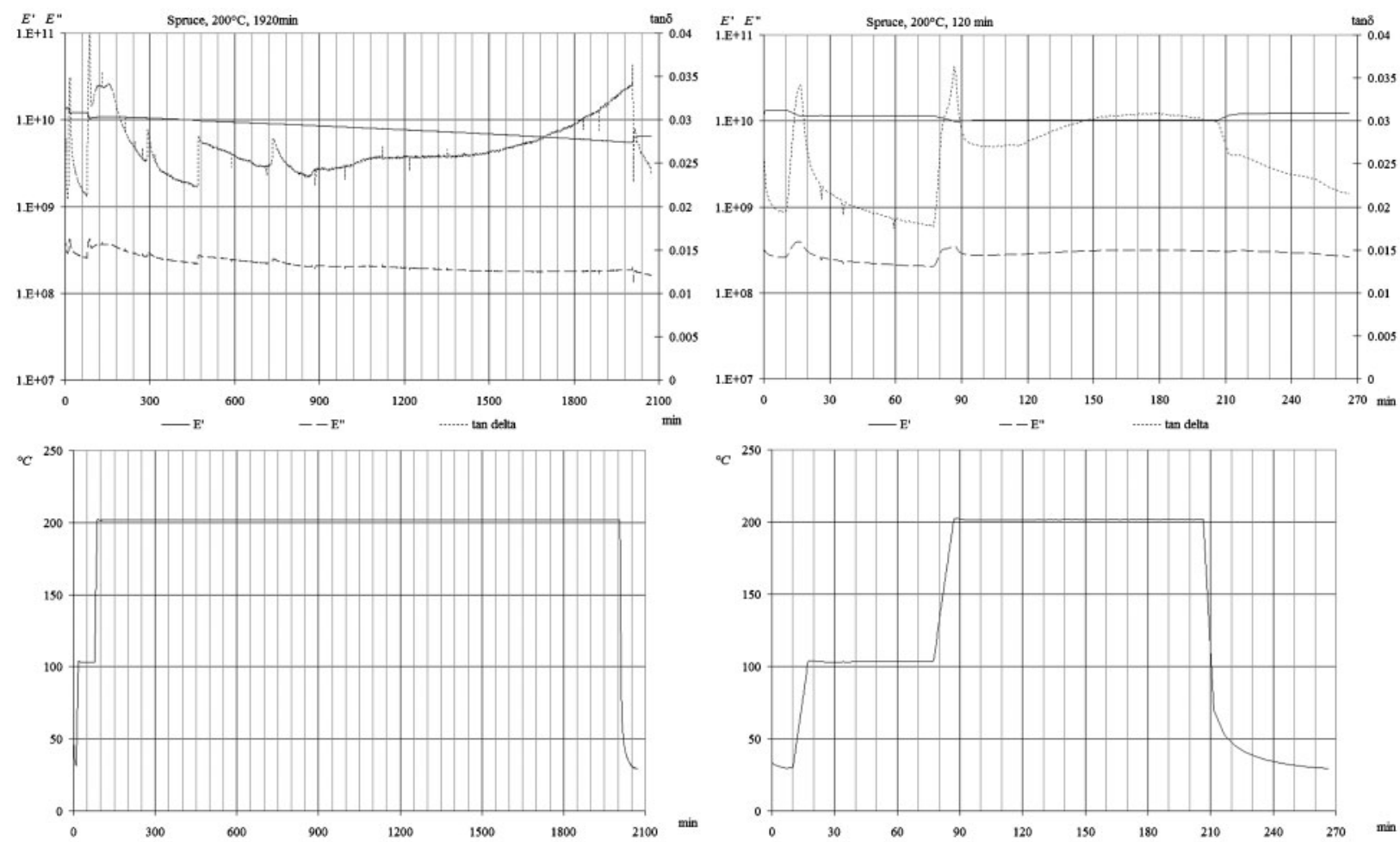

6 Viscoelastic behaviour of spruce specimens subjected to different soak times at $200^{\circ} \mathrm{C}$

storage modulus. When the predefined target temperature level was reached, the storage modulus $E^{\prime}$ continued to increase with time, approaching a steady state value, for specimens tested at 200 and $210^{\circ} \mathrm{C}$. In specimens tested at 220 and $230^{\circ} \mathrm{C}$, the increase was followed with short steady state and then decreased storage modulus $E^{\prime}$, which was more pronounced at $230^{\circ} \mathrm{C}$. At higher temperatures, 240 and $250^{\circ} \mathrm{C}$, the initial increase was followed by a rapid decrease of storage modulus $E^{\prime}$. The decrease of the storage modulus at temperatures 220 to $250^{\circ} \mathrm{C}$ as the time is prolonged, might be due to the movement of some small groups attached to the main polymeric components, including hemicellulose, lignin and cellulose, and breakdown of polymeric structures of the wood specimens, which was confirmed by the mass loss of the specimens during the DMA testing (Table 3). Furthermore, with temperature the loss modulus $E^{\prime \prime}$ was increasing until the target level of the temperature was reached. With time, the loss modulus decreased at all tested temperatures. Higher temperature of exposure resulted in bigger decrease in loss modulus $E^{\prime \prime}$. With temperature, the rate of decrease was increasing. The results showed that higher temperature in isothermal tests affected the wood's ability to dissipate energy considerably.

\section{Influence of time}

In Table 4, the results of a test series with beech specimen modified under $200^{\circ} \mathrm{C}$ and different soak times are summarised. As for increasing temperatures, the loss in dry mass, dry density and apparent/effective storage modulus (columns c, d, g and h) are as expected and decrease with an increase of soak time. The reduction of the effective loss modulus (column h) cannot be consistently linked to the holding time. If the change of $E^{\prime}$ of specimens $\mathrm{B} 01$ and $\mathrm{B} 12$ are compared, it can be noticed, that for the first one $\mathrm{E}^{\prime}$ increased while for the second one $E^{\prime}$ decreased. One possible reason for that could be the different strains that were applied B01 at $0.02 \%$ and $\mathrm{B} 12$ at $0.05 \%$. This has to be verified with further tests; however, in general, it already appeared that tests with a strain of $0.05 \%$ deliver more consistent results than tests with $0 \cdot 02 \%$ strain.

Table 4 Results of tests, influence of time, $200^{\circ} \mathrm{C}, 0.05 \%$ dynamic strain*

\begin{tabular}{|c|c|c|c|c|c|c|c|c|}
\hline a & b & c & d & e & $f$ & g & $\mathrm{h}$ & k \\
\hline & $t_{\mathrm{h}}$ & $\delta_{\mathrm{mo}}$ & $\delta \rho_{0}$ & $E_{\text {init }}^{\prime}$ & $E_{\text {fin }}^{\prime}$ & $\delta E_{\text {app }}^{\prime}$ & $\delta E_{\text {eff }}^{\prime}$ & $\delta E^{\prime \prime}$ eff \\
\hline No. & $\min$ & $\%$ & $\%$ & $\mathrm{GPa}$ & $\mathrm{GPa}$ & $\%$ & $\%$ & $\%$ \\
\hline B01* & 150 & $-5 \cdot 4$ & $-2 \cdot 5$ & $5 \cdot 08$ & $6 \cdot 23$ & $22 \cdot 6$ & $44 \cdot 7$ & $69 \cdot 1$ \\
\hline B12 & 150 & $\ldots$ & $\ldots$ & 8.58 & $7 \cdot 49$ & $-12 \cdot 7$ & $\ldots$ & $\ldots$ \\
\hline B12 & 300 & $\ldots$ & $\ldots$ & $8 \cdot 58$ & $7 \cdot 06$ & $-17 \cdot 7$ & $\ldots$ & $\ldots$ \\
\hline B12 & 450 & $-10 \cdot 7$ & $-6 \cdot 3$ & $8 \cdot 58$ & $6 \cdot 60$ & $-23 \cdot 1$ & $-6 \cdot 7$ & $-36 \cdot 7$ \\
\hline B13 & 600 & $-13 \cdot 3$ & -5.9 & $9 \cdot 62$ & $6 \cdot 49$ & $-32 \cdot 5$ & $-10 \cdot 0$ & $-54 \cdot 4$ \\
\hline B14 & 1080 & $-19 \cdot 3$ & $-10 \cdot 9$ & $9 \cdot 48$ & 4.79 & $-49 \cdot 5$ & $-29 \cdot 2$ & $-45 \cdot 5$ \\
\hline B21 & 2160 & $-27 \cdot 6$ & $-15 \cdot 9$ & $8 \cdot 56$ & $2 \cdot 85$ & $-66 \cdot 7$ & $-50 \cdot 8$ & $-40 \cdot 9$ \\
\hline
\end{tabular}

*B01 with 0.02\% dynamic strain. Symbols see Table 3, except: $t_{\mathrm{h}}=$ holding (soak) time. 

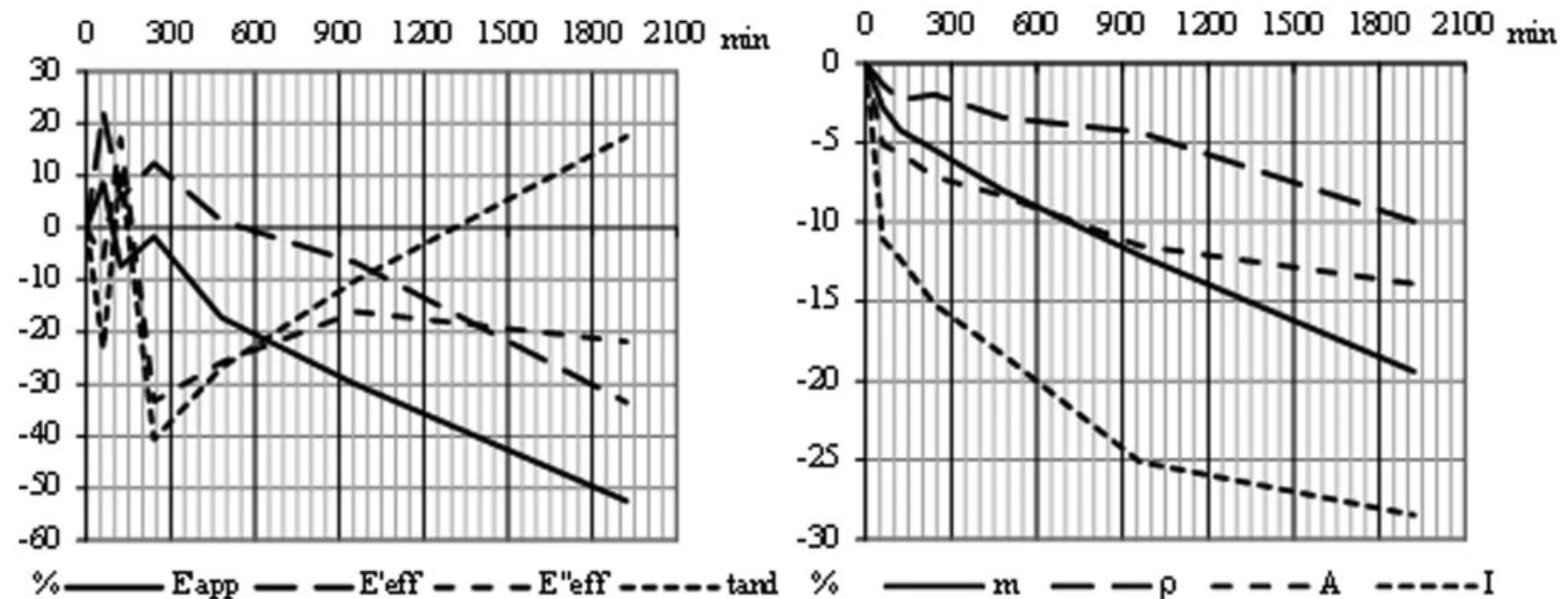

7 Viscoelastic (left) and geometrical/physical (right) behaviour of spruce specimens subjected to different soak times at $200^{\circ} \mathrm{C}\left(m_{0}=\right.$ dry mass, $\rho_{0}=$ dry density, $A=$ cross-section and $\mathrm{I}=$ moment of inertia, other symbols, see Table 3 )

For a series of spruce specimens, the test procedure was adapted according to the assumed flaws of the first test series. The heating phase was executed as a threestep approach which included soak times at 30 and $103^{\circ} \mathrm{C}$ and a cooling period back down to $30^{\circ} \mathrm{C}$ following the end of the treatment time (Fig. 6). This should ensure the complete removal of moisture before the temperature ramp up to the treatment temperature was initiated. Treatment times were $1,2,4,8,16$ and $32 \mathrm{~h}$. The viscoelastic data were compared at the end of both the initial and the final soak time at $30^{\circ} \mathrm{C}$.

In Fig. 6, the viscoelastic behaviour of two spruce specimens, one with a short and the other with a long treatment time, are shown. After a treatment time of $2 \mathrm{~h}$, only minor changes of the viscoelastic data can be observed if the heating and cooling phases are not being considered. For a treatment time of $32 \mathrm{~h}$, a significant reduction of the storage modulus can be observed. For the long time experiment, the storage and the loss modulus and as a function of them also $\tan \delta$ show some noise and as well three pronounced discontinuities over time. Such behaviour could be observed for most of the tests with long treatment times. The reason for this is not clear, but most likely, it should be attributed to the formation of microcracks in the wood and/or to an abrupt movement of the specimen on the supports following the dimensional changes due to the treatment. The three-point bending set-up does not provide a free movement of the specimen in longitudinal direction. This results in friction between specimen and supports, which might be suddenly released (partly) and thus lead to the observed unsteadiness. For the analysis, there was no correction applied to the data in order to filter out the effect of the discontinuities.

In Fig. 7, the results of the viscoelastic behaviour are summarised and compared to geometrical and physical changes that occurred over time at a treatment temperature of $200^{\circ} \mathrm{C}$. For short treatment times, it can be observed that the storage modulus increases slightly and only treatment times of more than $10 \mathrm{~h}$ at this temperature lead to a decrease of $E^{\prime}$. Both $E^{\prime \prime}$ and in particular $\tan \delta$ don't show a clear trend over time. It has to be considered that both of them are relatively small, $E^{\prime \prime}$ compared to $E^{\prime}$ and $\tan \delta$ as a result of this.
Therefore, both values are very sensitive to small changes and also signal noise. In order to use the damping ratio $\tan \delta$ as a parameter for the determination of a thermal modification/degradation, the DMA procedure has to be improved in such way, that discontinuities can be avoided or clearly be attributed to a distinct feature.

Different from the viscoelastic behaviour, the recorded geometrical and physical properties decrease also already at short treatment times which could be expected to be like this. The strong decrease of the moment of inertia is the main factor for the strong decrease of the apparent storage modulus.

If the data of Tables 3 and 4 as well as from Fig. 7 are compared, it can be seen that in our tests the thermal modification had a stronger effect on beech than on spruce. The effective storage modulus of beech decreased already at weaker modifications (shorter treatment time/ lower treatment temperature) where an increase could be observed for spruce.

\section{Conclusion}

Based on the preliminary results of the study, it can be concluded that DMA could be used successfully for studying mechanical behaviour of wood under isothermal, high temperature conditions that are used in the industrial thermal modification processes. The tests of beech and spruce specimens showed that integration of viscoelastic data into real time monitoring of a thermal modification process is possible. However, additional experiments are required. Namely, the preliminary tests revealed that:

- DMA data can be used for the identification of the intensity of a thermal treatment or degradation under the presence of oxygen. The unmodified storage modulus $E^{\prime}$ is best suited for this task

- the use of storage modulus and damping $\tan \delta$ for this purpose is less significant and has to be verified by further tests

- a three-point bending set-up delivered good results. However, the used test parameters have to be optimised, in particular the test geometry (higher slenderness) as well as strain rates 
- under identical conditions beech specimens showed a stronger degradation than spruce specimens

- owing to low specimen numbers, the obtained data are not statistically significant which requires additional tests

- air has to be replaced by an inert gas (nitrogen) in a later phase in order to study the thermal degradation under the absence of oxygen.

Further research will additionally focus on examination of the influence of the wood orientation on mechanical and/or viscoelastic response in order to determine intensity of the thermal treatment. Additionally, heating rate in relation to specimens' dimensions affecting the DMA results will be studied, while in 'large' wood specimens, temperature and moisture gradients can result in anomalies such as dual glass transitions. Furthermore, the glass transition temperature of the thermally modified wood will be determined to characterise its softening behaviour corresponding to a marked increase in molecular motion.

\section{Acknowledgements}

The authors would like to thank the COST Action FP0904 for financial support within the frame of Short Term Scientific Mission.

\section{References}

Assor, C., Placet, V., Chabbert, B., Habrant, A., Lapierre, C., Pollet, B., and Perré, P. 2009. Concomitant changes in viscoelastic properties and amorphous polymers during the hydrothermal treatment of hardwood and softwood. J. Agr. Food Chem. 57: 6830-6837.

ISO 6721-5. 1996. Plastics - Determination of dynamic mechanical properties - Part 5: Flexural vibration - non-resonance method. Geneva: ISO.

Laborie, M.-P. G. 2006. The temperature dependence of wood relaxations. A molecular probe of the woody cell wall. In Stokke and Groom, 87-94.

McCrum, N., Williams, B., and Read G. 1991. Anelastic and dielectric effects in polymeric solids. Dover: New York.

Menard, K. 2007. Dynamic mechanical analysis: a practical introduction. 2nd edn. Boca Raton, FL: CRC Press.

Militz, H. 2002. Thermal treatment of wood: European processes and their background. Proc. 33rd Annual Meeting. Cardiff, UK, May 2002. Institute for Wood Biology and Wood Technology. IRG/ WP 02-40241.

Olsson, A.-M., and Salmén, L. 1992. Viscoelasticity of in situ lignin as affected by structure: softwood vs. hardwood, in viscoelasticity of biomaterials. Washington, DC: American Chemical Society, 133143.

Salmén, L. 1984. Viscoelastic properties of in situ lignin under watersaturated conditions. J. Mater. Sci. 19: 3090-3096.

Sundqvist, B. 2004. Colour changes and acid formation in wood during heating. PhD dissertation. Lulę University of Technology, Division of Wood Material Science, Skellefta, Sweden.

Widmann, R., Fernandez-Cabo, J. L., and Steiger, R. 2012. Mechanical properties of thermally modified beech timber for structural purposes. Eur. J. Wood Prod. 70: 775-784. 